\title{
Un ancla en la nada. Interpretación de la lectura de M. Henry del concepto de angustia de S. Kierkegaard
}

\author{
An Anchor in Nothingness. An Interpretation of M. Henry's \\ Reading of S. Kierkegaard's Concept of Anxiety
}

\begin{abstract}
Resumen: El artículo analiza críticamente la lectura de Michel Henry del concepto kierkegaardiano de angustia. Primero explicita por qué para Henry la angustia ante la posibilidad como posibilidad y la inherente a la sexualidad conforman la «expresión paroxística» de la esencia de la vida. Luego muestra por qué para Kierkegaard la angustia no sólo es una experiencia de la vida como posibilidad de poder, sino también la experiencia de la posibilidad de la nada. Finalmente muestra cómo la tensión dialéctica entra ambas formas de la angustia conduce a la fe, y determina una noción no confesional del fenómeno.

Palabras clave: Angustia, Kierkegaard, Henry, vida, nada, fe.
\end{abstract}

\author{
ÁNGEL E. GARRIDO-MATURANO*
}

\section{Introducción}

El presente artículo se ocupará de analizar la lectura del concepto kierkegaardiano de angustia que el fenomenólogo francés M. Henry despliega en su libro Encarnación ${ }^{1}$. Ciertamente la cuestión que tenemos por delante es acotada, puesto que no es éste el lugar donde

Fecha de recepción: 09/09/2013. Fecha de aceptación: 19/11/2013.

Investigador independiente del Consejo Nacional de Investigaciones Científicas y Técnicas (CONICET) y Profesor de la Universidad Católica de Santa Fe, Argentina. Línea de investigación: fenomenología, filosofía de la existencia, filosofía dialógica. Publicaciones recientes: ¿Donde estás Señor? El acceso al fenómeno religioso en la filosofía fenomenológica, hermenéutica y existencial, Buenos Aires, Biblos, 2012. «Una cuestión de intensidad. La significación estético-religiosa del eros en el pensamiento de S. Kierkegaard», en: Revista de Filosofía de la Universidad Complutense de Madrid, Vol. 38, N. 1 (2013), pp. 1-21. Correo electrónico: hieloypuna@hotmail.com

1 Henry, M., Encarnación. Una filosofía de la carne, trad. J. Teira, G. Fernández y Ranz, Salamanca. Sígueme, 2001, en especial pp. 247-272. Sigla: E. 
el lector habrá de buscar un análisis exhaustivo y completo de El concepto de la angustia ${ }^{2}$, ni tampoco un estudio detallado de sus fuentes ni de las distintas interpretaciones que ha suscitado el genial libro de S. Kierkegaard a lo largo de la historia ${ }^{3}$. Por el contrario, aquí nos atendremos de modo puntual a analizar críticamente una cierta interpretación de la obra del autor danés, a saber, la henryana. El análisis persigue tres objetivos que no sólo se refieren, sino que se implican dialécticamente uno a otro, y que, según estimo, no pueden considerarse sino en conjunto. En primer lugar, determinar en qué sentido el análisis hermenéutico que Henry realiza de El concepto de la angustia desde los presupuestos de su propia fenomenología de la vida enriquece la noción kierkegaardiana, es decir, permite desplegar una dimensión ontológica esencial del fenómeno que en el planteo de Kierkegaard permanece sin duda ínsita o latente, pero, por cierto, no desarrollada. Me refiero concretamente a la descripción henryana de la angustia como «expresión paroxística» de la esencia de la vida en tanto pathos de sí o auto-afectividad. En segundo lugar estas consideraciones se proponen mostrar en qué sentido la lectura de Henry, aunque ciertamente enriquece, considerada unívocamente también y al mismo tiempo deja de lado una dimensión ontológica esencial del fenómeno que el análisis de Kierkegaard, según mi interpretación, advierte con toda seriedad. Me refiero concretamente a la angustia como experiencia no sólo de la vida como posibilidad de poder, sino de la nada como posibilidad. De acuerdo con ello, trataremos de mostrar en qué medida el pathos de sí que acaece en la angustia, precisamente por su carácter paroxístico, no sólo es una experiencia que la vida tiene de sí como posibilidad de poder, sino concomitantemente una experiencia de la posibilidad de la nada. Finalmente, en tercer lugar, intentaremos bosquejar brevemente en qué medida está tensión dialéctica que inevitablemente se establece en la angustia entre la auto-experiencia radical de la vida como posibilidad y la concomitante experiencia de la nada puede encontrar una «síntesis» en la fe, y qué es lo que en tal caso es posible entender por tal.

2 A mi modo de ver y hasta donde mi conocimiento alcanza, desde perspectivas diferentes, los dos mejores análisis de la cuestión en la obra de Kierkegaard son los siguientes: Grøn, A., Angst bei Søren Kierkegaard. Eine Einführung in sein Denken, trad. (alemana) U. Lincoln, Stuttgart, Klett Kotta, 1999. El libro, más que interpretar, expone y comenta de un modo detallado y minucioso, pero a la vez claro y libre de todo innecesario academicismo el texto de Kierkegaard como eje para realizar una introducción temática al conjunto de su pensamiento y revelar la articulación conceptual entre la constelación de problemas que es abordada en las obras de los diferentes pseudónimos. Desde una perspectiva más interpretativa y fuertemente influido por la fenomenología y el existencialismo hallamos, en segundo lugar, la hoy día quizás un poco anticuada (en lo que a la consideración de fuentes y bibliografía secundaria respecta), pero no por ello menos valiosa ni penetrante obra de Wahl, J., Études Kierkegaardiannes, París, Vrin, 1967, en especial pp. 210-256. En español una introducción a la cuestión de la angustia en el pensamiento kierkegaardiano puede leerse en: Suances Marcos, M., Sören Kierkegaard. Tomo II: trayectoria de un pensamiento filosófico, Madrid, UNED, 1998, en especial pp. 243-264. El vínculo de la angustia con la existencia inmediata y la relacional lo ha indagado Cañas, J. L., Sфren Kierkegaard. Entre la inmediatez y la relación, Madrid, Trotta, 2003, pp. 77-91.

3 Para la cuestión de la génesis, de la posición en el contexto de la filosofía y teología del S. XIX, como así también de las influencias reconocibles en El concepto de la angustia y de las distintas interpretaciones y repercusiones que la noción kierkegaardiana ha generado en el pensamiento contemporáneo nada mejor que remitir al lector a los distintos estudios que conforman la siguiente obra colectiva: Cappelørn, N. J./ Deuser, H., (eds.): Kierkegaard Studies. Yearbook 2001, Berlín, Walter de Gruyter, 2001. Dado que este artículo lee a Kierkegaard en clave fenomenológica, me parece, por último, particularmente importante remitir también al lector a otro excelente trabajo de Arne Grøn, en el que se considera en qué medida puede ser tomada la entera obra de Kierkegaard y, en especial, El concepto de la angustia y La enfermedad mortal como una fenomenología, esto es, como la descripción de estados de conciencia experimentados y percibidos por todo hombre en tanto tal. Me refiero a: Grøn, A., «Kierkegaards Phänomenologie?», en: N. J. Cappelørn y H. Deuser (eds.): Kierkegaard Studies. Yearbook1996, Berlín, Walter de Gruyter, 1996, pp. 91-116. 


\section{Henry lector de Kierkegaard}

\subsection{La angustia y la posibilidad en tanto tal}

Henry comienza su análisis de la cuestión que nos ocupa con las siguientes palabras: «El genio de Kierkegaard consiste en haber vinculado desde el principio el concepto de angustia al de posibilidad o poder.» ${ }^{4}$ Sin duda Kierkegaard ha establecido el maridaje esencial entre posibilidad y angustia, pero ¿por qué ello ameritaría, para Henry, el calificativo de genial? Simplemente porque de este modo se arranca el fenómeno de toda relación con una exterioridad mundana y se lo remite a la esfera de la auto-afectividad, es decir, al modo en que el existente se siente a sí mismo, siente su propia vida experimentándose a sí misma y, de ese modo, siente la esencia de la vida, que no es, por cierto, otra cosa que experiencia de sís. En efecto, Kierkegaard no remite la angustia a una relación con algo determinado o indeterminado, sino a la propia experiencia de la posibilidad. Tal cosa ya no constituye un modo de relacionarse con exterioridad alguna, sino de sentirse a sí mismo sintiéndose afectado por la propia vida como posibilidad de poder. Vinculando la angustia con la posibilidad y refiriendo la posibilidad al plano de la auto-afectividad, Kierkegaard habría remitido el fenómeno al plano trascendental (y no meramente psicológico). ¿En qué medida? Aquello que se nos revela en un mundo u horizonte de sentido, toda trascendencia, sólo puede revelarse como vivencia. Ahora bien, la vivencia en tanto tal es un modo de sentirse afectado por sí mismo en la inmanencia de sí. Yo no tengo una experiencia de algo, sino que me siento a mí mismo experimentando algo. Por lo tanto, si toda manifestación en el horizonte del mundo se da en y gracias a una vivencia de sí, entonces el sentirse a sí mismo o auto-afectividad es la verdadera esencia de toda revelación: aquello que posibilita la manifestación de cualquier trascendencia. De acuerdo con ello la angustia, en tanto experiencia de sí mismo como posibilidad de poder, constituye el origen afectivo último de cualquier poder concreto ejercido en el mundo. En efecto, la representación que el pensamiento se haga de lo posible y el ejercicio (trascendente) del poder son precedidos por y presuponen

$4 \quad$ E, p. 247.

5 La intuición genial de la filosofía de Michel Henry es la de la esencia de la vida. Para Henry, como buen fenomenólogo, el ser se agota en aparecer. Pero el aparecer se desdobla. Por un lado se manifiestan los entes del mundo y, por otro, la vida. En la manifestación de los entes mundanos impera la dualidad: una cosa es lo que se muestra, el fenómeno, y por otro aquel "afuera" trascendente en el que se muestra lo que se muestra, a saber, el horizonte de visibilidad, proyectado extáticamente por el sujeto, que determina el cómo del aparecer del fenómeno, esto es, el mundo. Por otro lado se manifiesta la vida. Su modo de manifestación es radicalmente diferente del aparecer de los entes en el mundo, porque en ella impera la identidad absoluta entre la manifestación y lo que se manifiesta y porque tal manifestación se cumple en una absoluta inmanencia. La vida no revela otra cosa que sí, sino que se revela a sí misma en la auto-experiencia afectiva de sí que tiene cada viviente. El viviente se experimenta a sí mismo, experimenta su propia vida y, en esa experiencia, la vida se experimenta a sí misma, se auto-afecta. Aquí la esencia de la vida -el experimentarse a sí misma, el sentirse a sí misma viviente- y la manifestación de la vida -nuevamente el sentirse o experimentarse a sí misma en la inmanencia de la auto-afección- son lo mismo. En ella la esencia de la manifestación y la manifestación de la esencia son una y la misma cosa. El mundo y los entes son, pero no experimentan su ser ni se manifiestan a sí mismos. La vida es vida porque se experimenta a sí misma viviendo y, haciéndolo, se auto-manifiesta. Declara Henry: «Esto que tiene la experiencia de sí, lo que [se revela como] gozo de sí y no es otra cosa que este puro gozo de sí mismo, que esta pura experiencia de sí, es la vida». Henry, M., L'essence de la manifestation, París, Presses Universitaires de France, 1963, p. 354. 
la experiencia (inmanente) de la posibilidad de poder. Y ello es precisamente lo que, según Kierkegaard, angustia. En haber, ante todo, referido el fenómeno a la experiencia inmanente de la posibilidad de poder (libertad como posibilidad), en haber, luego, advertido que no es posible librarse de esta experiencia, pues la vida ya siempre se experimenta a sí misma como posibilidad (realidad de la libertad); y, finalmente, en señalar que la experiencia de la libertad como posibilidad de poder es la condición desde la cual se ejerce toda elección de una cierta posibilidad concreta (posibilidad para la posibilidad), radica la originalidad trascendental y la profundidad de la definición kierkegaardiana de la angustia, a saber: «realidad de la libertad como posibilidad para la posibilidad.» ${ }^{6}$ Esta intuición decisiva de Kierkegaard lo lleva a Henry a calificarlo como «el inventor de una fenomenología radical.» ${ }^{7}$ El danés habría desplegado una fenomenología de la vida avant la lettre que describe el encontrarse de esta última ya siempre afectada por sí misma en su inmanencia como posibilidad de poder.

Henry ve reforzada su interpretación por el vínculo que se establece en El concepto de la angustia entre este fenómeno y la inocencia. En efecto, la inocencia, concebida como ignorancia, se vuelve aquel estado de paz y reposo en el que no hay nada (objetivo) que pueda distinguirse como bueno o malo, pero en el que, sin embargo, comienza a crecer la angustia ante esa misma nada, o, mejor dicho, ante la experiencia de la pura posibilidad que late en estado de reposo. Cuando ello ocurre se consuma la reducción de la objetividad que realiza Kierkegaard en su fenomenología radical de la angustia, pues lo posible que la genera queda situado ya no en el campo del pensamiento, que puede representarse algo como nocivo o malo, «sino en la inmanencia radical de la vida, de la cual la inocencia nos proporciona un pathos ejemplar ${ }^{8}$. La inocencia nada sabe de lo que es bueno o malo, pues ella es ignorancia. Pero tampoco tiene conocimiento de sí como inocencia, pues si así fuera ya no sería inocente. La inocencia escapa de todo saber del pensamiento y sólo se experimenta a sí misma en la inmediatez de su propio pathos. Ahora bien, experimentándose a sí misma, experimenta angustia. La angustia de quien sabe que puede ser y no sabe nada acerca de qué puede ser. Esta angustia ante la posibilidad como tal, esta angustia, que, propiamente hablando, es angustia por nada, estremece nuestro cuerpo viviente (o «carne», para utilizar la expresión henryana) y está a la base del modo en que el hombre se siente a sí mismo en el desarrollo de cada una de sus actividades, incluso las más inocentes. Pues por muy inocente que la inocencia sea, por muy ignorante que se sea del mundo, habita siempre en la inocencia una angustia secreta: la de eso que es nada pero que puede ser. Al no saber nada de lo que se puede, en la inocencia la posibilidad de poder se exacerba hasta que la angustia traspasa a la inocencia por completo y «le confiere el pathos que le es propio, (...), ese estado inestable en virtud del cual, no siendo culpable porque todavía no ha hecho nada y no sabe nada de lo que puede hacer (...), se encuentra ya invadida por la posibilidad de hacerlo, (...), sumergida por la angustia de esta libertad vertiginosa» ${ }^{9}$. Y tal es el vértigo angustiante que ocasiona la libertad ante la inevitable posibilidad de poder llegar a ser el sí mismo que se ha de ser, que el sujeto quiere huir de sí, de su propia vida, anegarse en la relación con lo inmediato

6 Kierkegaard, S., El concepto de la angustia, trad. José Gaos, Buenos Aires/México, Espasa Calpe (Colección Austral), ${ }^{4} 1952$, p. 46 (cursivas mías). Sigla: $C A$.

7 E, p. 248.

8 E, p. 250 .

9 E, p. 251. 
y no elegirse a sí mismo. Pero nunca logra hacerlo, porque por el mero hecho de vivir nos sentimos vivos; y sentirnos vivos es de suyo sentirnos afectados por la posibilidad de poder. Entonces, en un intento desesperado por librarse de sí misma, la posibilidad de poder resulta rechazada hacia sí misma, hacia el poder que ella hace posible. «Entonces se lanza en él, como hacia la única salida, la única posibilidad que le queda, y pasa al acto» ${ }^{10}$. Es el fin de la inocencia. Ahora el sujeto sabe que es elección de y relación a sí en la elección de su posibilidad de relación con lo otro. Ahora sabe, para decirlo en el lenguaje de Kierkegaard, que es espíritu y que puede o no puede asumir su condición de tal. Ahora existen -mucho antes que en términos morales en términos ontológicos- el bien y el mal.

Este extraño proceso de repulsión y atracción conjuntas - de antipatía simpatética o de simpatía antipatética- que se da en la angustia, la cual quiere al mismo tiempo huir de la posibilidad y saltar en ella, es, para Henry, el testimonio por excelencia de la relación de la vida con sí misma. Por un lado la vida, en cuanto viviendo confiesa su anhelo de querer vivir, es deseo de experimentarse a sí misma, de gozar de sí cada vez con mayor intensidad en todo lo que es y puede ser, de experimentar, por tanto, el crecimiento de las distintas posibilidades de sentirse a sí mismo. Pero, por otro lado, en este acrecentamiento constante de sí, la vida se sufre a sí misma. Experimenta la imposibilidad de desligarse de sí, de sus sufrimientos y de sus limitaciones. Dicho de otro modo: padece su propio vivir como un lastre que pesa sobre sí. Entonces, quiere negarse a sí misma, deshacerse de sí. Pero es un deseo imposible de cumplir, porque la vida es constante experiencia de sí, y negarse a sí misma no es sino un modo de experimentarse a sí. La imposibilidad de romper el lazo que liga a la vida a sí misma, de escapar al propio sufrimiento de sí y a las propias posibilidades y, consecuentemente, «el sentimiento de sí como la imposibilidad por principio de escapar a sí (...) culmina finalmente y se resuelve en la angustia» ${ }^{11}$. Pero precisamente porque en la angustia la vida experimenta esta imposibilidad de deshacerse de sí, es decir, experimenta la imposibilidad de negar el hecho de que ya siempre se siente afectada por sí misma como posibilidad de ser, la vida alcanza en la angustia la experiencia paroxística de sí, la experiencia de su inevitable ligazón a sí misma y, de este modo, se experimenta a sí misma en su esencia con la mayor intensidad posible. De allí que la entera interpretación henryana del concepto de la angustia en Kierkegaard pueda desembocar en la siguiente afirmación:

«La angustia no es más que la expresión paroxística de la esencia del sí, del pathos en el que, unido a sí y convertido de este modo en el sí que es, se halla investido para siempre de esa posibilidad de poder que es su libertad infinita.» ${ }^{12}$

Pero Henry es consciente de que Kierkegaard, a partir del capítulo II de su obra, expone otra explicación distinta de la angustia, que ya no parece referirse directamente a la relación del sí mismo con su propio sí, esto es, con su vida que se experimenta a sí misma como libertad para la posibilidad en tanto tal, sino que parece provenir de algo externo: del cuerpo y su pecaminosidad.

10 E, p. 252.

11 Henry ,M., La barbarie, París, Grasset, 1987, p. 128.

12 E, p. 254. 


\subsection{La angustia y la posibilidad del pecado}

Como es ampliamente conocido, para Kierkegaard el hombre es una síntesis de cuerpo y alma puesta por el espíritu. Desde un punto de vista fenomenológico podemos entender por cuerpo el cuerpo meramente físico, cuyos miembros y órganos funcionan de acuerdo con una serie de procesos fisiológicos determinados. Por alma entendemos nuestro cuerpo en tanto «carne viviente» ${ }^{13}$, es decir, el conjunto de las impresiones de nuestros sentidos, de nuestras percepciones y de las sensaciones resultantes del ejercicio de nuestros poderes. El espíritu que los reúne es la posibilidad de experimentar como propias esas sensaciones o impresiones del alma que resultan de la actividad de nuestro cuerpo, y, consecuentemente, de relacionarse con ellas de un modo u otro, en función de una u otra posibilidad de ser. De esta manera, el espíritu conjuga o sintetiza a ambos, alma y cuerpo, en el sí mismo, que precisamente es posibilidad de ser.

Sin embargo, se trata de una síntesis paradójica entre dos heterogeneidades radicales. En primer lugar, porque el espíritu experimenta como sensaciones de su propia alma las que le llegan a través de un cuerpo que, considerado en sí mismo como puro objeto físico, no siente nada. En segundo lugar, porque el espíritu se relaciona libremente con las sensaciones e impresiones de un cuerpo que, en cambio, está determinado por la naturaleza. Y, en tercer lugar, porque el espíritu es infinito en lo que respecta al querer de su voluntad libre, que no se halla sometida a la corrupción de la materia, pero que sólo puede realizarse en relación con lo finito psico-físico, sujeto a la determinación natural y a la corrupción material. Antes esta enorme contradicción, resultante de la heterogeneidad que existe entre el espíritu y el cuerpo el espíritu se angustia. Y esta angustia alcanza su ápice cuando ese mismo espíritu entra en relación con el cuerpo allí donde éste se halla más fuertemente determinado por la naturaleza y el instinto. Me refiero a la sexualidad.

El espíritu, que siente sus sensaciones como suyas, se descubre como espíritu de un cuerpo sexuado. El momento de ese descubrimiento es un momento de angustia, pues $-\mathrm{y}$ he aquí para Henry una nueva intuición fulgurante de Kierkegaard- «lo sexual es la expresión de la profunda contradicción implícita en que el espíritu inmortal esté determinado como genus» ${ }^{14}$. El testimonio de lo angustiante de la contradicción es el pudor, a través del cual el espíritu confiesa hallarse determinado por las sensaciones provocadas por la diferencia sexual que marca al cuerpo, en lugar de ser él quien determina la síntesis en que han de encontrarse cuerpo y alma. Por ello puede escribir Kierkegaard que «la verdadera significación del pudor es que el espíritu no puede declararse, por decirlo así, a la altura de la síntesis» ${ }^{15}$. La angustia, en esta nueva forma suya testimoniada en el pudor, es, entonces, para Henry, la disposición afectiva a través de la cual el espíritu o sí mismo experimenta que se halla de-terminado por algo que le es completamente heterogéneo, pero a lo que, sin embargo, se halla irremisiblemente ligado. Me refiero precisamente a su cuerpo objetivo marcado por la diferencia sexual. Se trata de la angustia que el espíritu padece cuando experimenta que la libre posibilidad de síntesis que él es y no puede dejar de ser se halla en contradicción con el impulso ciego de su cuerpo sexuado

13 Que Henry identifica el alma con el cuerpo o carne viviente queda claro de pasajes como el siguiente: «El alma, es decir, también nuestra carne viva (...).» E., p. 255.

$14 C A$, p. $75 ;$ E. p. 257.

$15 C A$, p. 74. 
que pretende determinar las posibilidades del sí mismo. Dado el carácter insuperable de esta contradicción, la angustia crece más y más, hasta que, para deshacerse de sí misma, salta en el pecado, es decir, decide libremente esclavizarse al impulso ciego, para que sean las pasiones que dominan al cuerpo sexuado quienes determinen las posibilidades que debería haber determinado el propio espíritu.

Dado el salto, está puesto el pecado. Pero -nos advierte Kierkegaard- «la sensibilidad no es la pecaminosidad» ${ }^{16}$. Y nos reitera que «lo sexual como tal no es lo pecaminoso» ${ }^{17}$. Sólo llega a serlo porque, sumido en angustia, el espíritu libremente elige negarse a sí mismo: antepone la esclavitud del deseo a la libertad de la voluntad, y somete sus posibilidades al imperio de los sentidos. Sin embargo, no es la angustia la que causa el pecado. La angustia nos coloca al borde mismo del salto en él, pero el que salta libremente en la cualidad del pecado es el espíritu, que se doblega ante la angustia y se entrega a la disipación. Henry se pregunta si la angustia subjetiva ante la pura posibilidad como tal y esta segunda forma objetiva de la angustia como angustia ante la posibilidad de pecar, experimentada por antonomasia en la sexualidad, son efectivamente dos formas diferentes. Esta última pareciera estar vinculada con una exterioridad mundana (el cuerpo sexuado) y la otra referida a la pura inmanencia del espíritu en tanto que posibilidad. Sin embargo la interpretación de Henry reafirma la idea de que se trata de dos manifestaciones de una misma angustia. ¿En qué medida?

En lo sensible distingue Henry una dualidad. Por un lado esta lo sensible en el sentido de aquello que puede ser sentido - la lisura de una madera-, pero que por sí mismo no siente nada. Por otro lo sensible en el sentido de aquello que posee la capacidad de sentir y está determinado por ello -los seres vivientes. En nuestro cuerpo se reproduce esta dualidad. Él es comprendido como aquello que puede sentir todo lo que es sensible, pero reducido a su condición de cosa material, convertido en una mera secuencia de procesos fisiológicos y privado de su vida concebida como capacidad de auto-afectarse, él no siente nada. El ojo no ve. Es el alma (nuestra carne viviente en tanto susceptible de sentirse a sí misma sintiendo lo sensible) la que ve. Cuando nuestro cuerpo cósico es intencionado (por el espíritu) como una carne investida de la capacidad de sentir (como alma) «se produce una modificación esencial: lo sensible se convierte en lo sensual, la sensibilidad se denomina ahora sensualidad» ${ }^{18}$. Los cuerpos son sensuales porque llevan en sí el espíritu ${ }^{19}$. La sexualidad es precisamente el punto donde el cuerpo, transido por el espíritu y convertido en alma, más extremadamente se siente a sí mismo en su diferencia radical respecto de otros cuerpos. Consecuentemente es el lugar donde su sensibilidad deviene sensualidad en el más alto grado. De acuerdo con ello, el impulso sexual es la ex-presión de la posibilidad del sujeto de asir al otro donde éste se siente más intensa e íntimamente a sí mismo. Es, en otras palabras, la expresión de la posibilidad de tocar el espíritu del otro. Ahora bien, ésta no es una posibilidad fáctica cualquiera. Lo que experimenta todo hombre cuando siente en su propia carne esta posibilidad de tocar la vida misma del otro «en realidad es la capacidad de poder» ${ }^{20}$, es decir, el hecho de que el sí mismo tiene la posibilidad de poder y, concretamente, de poder incluso tocar la esencia de otro sí. Precisamente de esta

$16 C A$, p. 85.

17 CA, p. 74.

18 E, p. 262.

19 Cf. E, p. 263.

20 Loc. cit. 
posibilidad de poder es de la que surge la formidable angustia ante, por ejemplo, la posibilidad de acariciar la mano de la joven que se sienta a mi lado. En el deseo sexual despierta, entonces, no una angustia diferente de la angustia ante la posibilidad, sino una nueva expresión paroxística, un modo paradigmático de la misma angustia, que se manifiesta siempre como angustia ante la posibilidad de ejercer mi poder, pero concretamente ahora como aquel ápice de la angustia que resulta de la posibilidad de ejercer aquel poder que más me seduce: el de tocarme o sentirme a mí mismo con la mayor intensidad tocando al otro en su propio espíritu.

Henry concluye que, cuando en la realidad efectiva estas dos fuentes de una misma angustia, la angustia ante la posibilidad en tanto tal y la angustia ínsita en la sexualidad, se reúnen, entonces se «mezclan sus aguas como dos torrentes en un solo caudal que lo va a sumergir todo ${ }^{21}$. Cuando a la angustia surgida de la contradicción enorme del espíritu de tener que realizarse a través de un cuerpo determinado por su sexualidad se suma la angustia con la cual ese mismo espíritu despierta a su extraordinario poder, incluso el poder de «tocar» el espíritu del otro allí donde ese espíritu se une más íntimamente con el cuerpo -en el sexo-, entonces la angustia se reduplica y crece hasta punto tal de volverse insoportable. Es ahora cuando el sujeto experimenta el irrefrenable deseo de desembarazarse de ella. Y como no puede hacerlo, porque él es espíritu y el espíritu es posibilidad de poder, y como, además, esa posibilidad no puede librarse tampoco de su vínculo con el cuerpo y sus pulsiones, porque el espíritu es síntesis de cuerpo y alma, entonces el sujeto termina saltando en la angustiosa posibilidad de la sensualidad y peca. Pero el hombre -reitero- no peca por la sensualidad misma, sino por quemar en las llamas de la hoguera sexual su espíritu y su libertad. Su pecado, antes que y como condición de todo pecado moral, es ontológico: peca porque quiere liberarse de su sí mismo esencial, de ese espíritu que pesa sobre sí y que se deja sentir como angustia. Pero, claro, esto no puede hacerlo nunca, pues él es espíritu; y apenas ha saltado surge una nueva posibilidad, un nuevo deseo irrefrenable, una nueva angustia. Entonces es necesario volver a saltar. Desde este momento con el pecado adviene también la pecaminosidad en el mundo: el constante aumento cuantitativo del pecado surgido de cada salto cualitativo.

Hasta aquí los trazos esenciales de la lectura henryana del concepto de la angustia en Kierkegaard. ¿En qué medida ella implica una ganancia en el despeje de la esencia de la angustia? ¿En qué otra no lo es?

\section{La vida y la nada o la ambigüedad de la angustia}

Sin duda el logro más notable de la lectura henryana de Kierkegaard radica en haber visto la relación -latente en el propio concepto kierkegaardiano de angustia, pero recién explicitada en sus últimas consecuencias por el fenomenólogo francés desde su propio trasfondo filosóficoentre la angustia y la esencia de la vida. Arne Grøn en su libro Angst bei Søren Kierkegaard llamaba la atención sobre el hecho de que el punto central de la teoría de Vigilias Haufniensis consiste en poner en claro lo que la angustia muestra ${ }^{22}$. Pues bien, Henry ha puesto en claro que la angustia muestra o, mejor dicho, es el modo a través del cual se muestra a sí misma de un modo paroxístico o hiperbólico, la esencia de la vida. En efecto, la angustia nos saca de

21 E, p. 264.

22 Cf. Grøn, A., Angst bei Søren Kierkegaard, p. 14 y p. 61. 
nuestro abotagamiento en la inmediatez, de nuestra repetida tendencia a interpretarnos como una cosa «en sí» entre las otras cosas «en sí», y nos descubre que todo ello no es sino un sueño del espíritu; que estamos vivos, que la vida no es una cosa definitiva encerrada en sí, sino que se afecta a sí misma toda vez que sentimos, aún incluso en medio de aquel abotagamiento en la inmediatez, la angustiosa posibilidad de ser. La angustia es simultáneamente la experiencia de una libertad esencial y de una no libertad esencial. La libertad, vivenciada en la angustia en su raíz ontológica última, no es sino la experiencia de aquel sentimiento por el cual la vida se siente a sí misma como el poder originario y fontanal del que brota todo otro poder. Que la angustia -que es esencialmente afectiva- sea la experiencia de la libertad como posibilidad, testimonia que la libertad esencialmente, es decir, antes y como condición de su ejercicio a través de la actividad de la voluntad, se manifiesta o aparece -se fenomenaliza- como aquel afecto o auto-afección por la cual la vida se siente a sí misma fuente de todo poder y de toda posibilidad. La libertad se manifiesta, así, antes que como una abstracta potencialidad de la voluntad, como una concreta experiencia afectiva, precisamente como la experiencia por la cual la vida adviene a sí o se siente a sí como posibilidad. Es precisamente esa experiencia de la libertad la que angustia. Henry advierte con claridad que la angustia kierkegaardiana, al reducir toda objetividad y remitir el fenómeno a la inmanencia del espíritu como pura posibilidad, muestra que la libertad no es sino el sí mismo o espíritu viniendo a sí mismo, es decir, la vida experimentando su propia esencia, que no es otra cosa que relación a sí, cuyo modo originario es sentirse afectado por la propia libertad. Por ello mismo podría decirse que lo que angustia es la vida. En última instancia esta aseveración coincide con la idea kierkegaardiana de que la angustia es propia del espíritu y de que, cuanto más espíritu, más angustia, pues el espíritu como relación a sí no es sino la vida viniendo a sí misma, sintiéndose a sí misma; y, cuanto más intensamente se siente, cuanto mayor es la relación y la presencia a sí, tanto más experimenta su libertad y sus posibilidades y tanto más se angustia. Pero, además, en la angustia kierkegaardiana se experimenta una no libertad esencial, a saber, la imposibilidad del espíritu de no ser libertad. En ello ve con acierto Henry nuevamente un testimonio de la esencia ontológica de la vida, que no puede sino una y otra vez venir a sí misma y experimentarse a sí misma. El viviente no puede dejar de vivir, así como el espíritu, por mucho que le angustie su condición y trate de evadirla, no puede dejar de ser espíritu, pues todo intento de absorberse en lo sensible finito no es sino una decisión libre del espíritu; así como todo intento de la vida de cosificarse y no sentirse a sí misma como posibilidad no es sino un modo de experimentar la vida. En la angustia, como destaca la lectura filosófica de Henry, no sólo se experimenta el sí mismo como tal, esto es, como sí mismo viviente, auto-afectado por su vida bajo la forma de la libertad, sino también y a la par experimenta la imposibilidad de desligarse de esa vida misma que constituye su esencia. Justamente por eso la angustia configura, por antonomasia, una experiencia paroxística o hiperbólica de sí, esto es, de la propia vida. Tal experiencia tiene un modo ejemplar o paradigmático en la angustia que genera la sexualidad. Pues es allí donde in concreto el existente experimenta con mayor intensidad su poder, a saber: el poder de sentirse vivo sintiendo la vida del otro; y, a la par, la imposibilidad de librarse de este poder, a saber: la imposibilidad de negar la propia sexualidad y, consecuentemente, de no sentirse a sí mismo sintiendo al otro. Como experiencia concomitante de la vida como posibilidad y de la imposibilidad de librarse de la vida, la sexualidad es a la vez un caso paradigmático de la angustia y de la experiencia paroxística de sí como un sí mismo viviente. De allí que el análisis 
que realiza Henry de la segunda forma de la angustia, como angustia ante la posibilidad de pecar, no sólo converja con la primera, sino que resulte su modo ejemplar por excelencia. Pero si Henry ha visto y desplegado las consecuencias de la relación entre la esencia de la vida y la angustia que laten en el texto de Kierkegaard, no ha calado suficientemente hondo en lo que Kierkegaard sí ha visto con plena seriedad: que en la angustia nos relacionamos no sólo con la posibilidad como nada, sino con la posibilidad de la nada.

Si bien es cierto que la angustia es una auto-experiencia paroxística de la vida, ella no sólo se experimenta a sí misma con la mayor intensidad cuando vivencia su ser como poder, tal cual ocurre en la sexualidad. También y de modo dialéctico la vida se experimenta a sí misma, experimenta que es y puede ser, y lo hace con la mayor intensidad posible cuando vivencia la posibilidad concreta de su aniquilación. No hay, quizás, experiencia más intensa de la vida, no hay instante en el que ella quiera aferrarse más a sí misma y a sus posibilidades, no hay momento en el que sienta más agudamente que es poder ser que en la angustia que la pone cara a cara con la amenaza del no ser, de la imposibilidad radical, de la nada y de la muerte. La angustia nos permite sentirnos afectados por nuestra propia vida como posibilidad no sólo descubriendo la posibilidad como nada, como un «aún no» indeterminado, sino en tanto ella es concomitantemente la disposición afectiva a través de la cual se nos descubre la posibilidad de la nada como aquella posibilidad suprema en la que se podrían disolver todas las demás. Es ésta la ambigüedad dialéctica más esencial del fenómeno: la de descubrirnos, a través de la posibilidad, a la par la vida y la nada. Revelándonos nuestro ser como pura posibilidad, que, por lo pronto, es nada, concomitantemente la angustia nos descubre la posibilidad de que ese ser, al fin y al cabo, se disuelva en nada. A Kierkegaard no le fue extraño este significado de la angustia. Precisamente por ello el capítulo en el que se resuelve su libro lleva por título «la angustia en unión con la fe como medio de la salvación». Él era plenamente consciente de esta irreductibilidad de la posibilidad de la nada a la posibilidad como nada; era consciente, dicho de otro modo, de la posibilidad de que no haya ningún absoluto y de que, al fin y al cabo, todo esté perdido. Porque conocía la angustia, sabía perfectamente que nuestro destino solitario puede que no sea otro que el de ser olvidados por Dios:

«En lo más íntimo de cada hombre vive, sin embargo, la angustia de que él en el mundo podría esta solo, olvidado de Dios, en la monstruosa economía de millones y miles de millones. Se trata de mantener esta angustia lejos, en la medida en que se ve a muchos en torno nuestro, algunos ligados a nosotros como parientes y otros como amigos; pero a pesar de esto la angustia sigue allí, y casi que uno no se atreve a pensar, cómo habría de sentirse si se viera privado de todos ellos.» ${ }^{23}$

La posibilidad de la nada, concretamente la posibilidad de que, a nivel individual, nuestra vida corra hacia un vacío tenebroso que llamamos muerte, y la posibilidad de que, a nivel cósmico, la vida entera del universo no sea otra cosa que una carrera hacia el frío y la oscuridad últimos, es irreductible. Hagamos lo que hagamos, aferrémonos a lo que nos aferremos nunca podremos apartarnos del todo de esas posibilidades amenazantes. Para ello en nada nos ayuda

23 Kierkegaard, S., Søren Kierkegaards Papirer (Bd. I-XI), Hrsg.Von P. A. Heiberg, V. Kuhr und E. Torsting, Kopenhagen, 1909-1948, VIII 1 A, p. 363. 
tampoco el conjunto del conocimiento humano, que no sólo no puede suprimirlas, sino que, de la mano de la ciencia y la cosmología contemporáneas, que hubieran aterrado a Kierkegaard, las azuza. Ante tal angustia no es el conocimiento, sino la fe lo único que puede mitigar el desasosiego del temible «quizás». Quizás hoy mismo estemos ya empezando a precipitarnos en el abismo insondable. ¿Quién podría afirmar lo contrario? Por eso mismo Kierkegaard une la angustia con la fe como único medio de salvación. Tener fe es creer que la nada es una amenaza que se disolverá como los vapores de la noche con el amanecer y que la libertad, en tanto pura posibilidad indeterminada, es en realidad tan sólo un mero «aún no» que, llegado el instante, será un «ahora sí» pleno de sentido, aun cuando esa plenitud se nos escape. Tener fe es superar el desasosiego de la amenaza de la nada y del sinsentido final y empuñar con gozosa intensidad cada instante de la vida como propia. Es, en una palabra, lo contrario de la desesperación del que quiere embotarse en lo finito y huir del fuego de la vida en él, porque no puede soportar el abismo de muerte y de nada que ineluctablemente se recorta a la sombra de sus llamas. Kierkegaard, porque advertía la necesidad de la fe, advertía también esta inquietante presencia no sólo de la posibilidad como nada, sino a una con ello de la posibilidad de la nada, abierta por la angustia. Por ello advirtió también que el discípulo de la posibilidad sabe, como sabe un niño su $\mathrm{ABC}$, «que no puede exigir absolutamente nada de la vida, que lo espantoso, la perdición, el anonadamiento moran pared por medio con todos los hombres.»24 Siendo así, el hombre educado en la escuela de la posibilidad nada puede, por cierto, exigir de la vida, porque no hay manera cierta de suprimir la amenaza de la nada que se hace patente con ella. Al respecto sólo cabe tener fe. Henry tenía razón. Es indisputable que en la angustia sentimos, incluso paroxísticamente, la vida, y que la sufrimos y gozamos como libertad y posibilidad. Pero el genio de Kierkegaard nos dice que «en la posibilidad es todo igualmente posible, y quien ha sido verdaderamente educado por la posibilidad ha entendido lo espantoso no menos que lo agradable» ${ }^{25}$. Quien comprende verdaderamente que en la posibilidad todo es igualmente posible, comprende también que es posible que la suprema posibilidad de la vida sea el anonadamiento y que todo sentido augurado en lo posible se precipite en el sinsentido de la imposibilidad final. Es entonces cuando la angustia muestra su más radical ambigüedad y se nos aparece como si fuera una bailarina que gustase de danzar en el vilo que separa la vida de la nada. Pero no se puede jugar en el vilo sin caer hacia un lado u otro. La tensión inmanente a la angustia es tan grande, que el angustiado tiene que saltar. Y salta hacia la oscuridad de la desesperación o al débil resplandor de la fe.

\section{La fe}

En modo alguno el análisis kierkegaardiano de la angustia constituye un «argumento» en favor de ninguna tesis confesional, ni tampoco un intento encubierto de demostrar por vía de la psicología la realidad del objeto de la fe, entiéndaselo como se lo entienda. Hay que tomar en serio la frase con la que Kierkegaard cierra El concepto de la angustia: «Tan pronto como la Psicología ha concluido con la angustia, hay que entregar ésta a la Dogmática.» ${ }^{26}$ El aná-

\footnotetext{
$24 C A$, p. 164.

25 Loc. cit.

$26 C A$, p. 171.
} 
lisis de la angustia nos coloca todo lo más cerca posible de la necesidad del salto, ya sea en la desesperación y el pecado, ya sea en la fe, pero ni nos hace saltar, ni nos dice nada acerca de lo que hay en la otra orilla. El análisis kierkegaardiano nos muestra que todo hombre, por su propia constitución ontológica -por ser espíritu, es decir, posibilidad de sí, que, como tal, implica la posibilidad de sí mismo como nada- experimenta no la fe, sino la necesidad de la fe. En efecto, la angustia nos muestra que ante la amenaza de la nada en su doble aspecto, que en el fondo es uno y el mismo -el de la nada como el sinsentido en el que siempre pueden terminar todas nuestras posibilidades y el de la nada como la consumación final del sinsentido con el anonadamiento de la vida- necesitamos de la fe para no hundirnos en la desesperación. De este modo, la angustia se revela como una ocasión para la fe. Y como todo hombre, por su propia condición de tal, experimenta angustia, ella es una ocasión que no se le niega a nadie. Pero allí termina su servicio a la dogmática. Que el hombre luego salte desde el regazo de la angustia y ponga pie firme en la fe, o que, por el contrario, salte en sentido contrario y la niegue, es algo de lo que ni el análisis fenomenológico de la angustia ni, por cierto, ningún otro análisis pueden dar cuenta; si por «dar cuenta» entendemos «probar» o «demostrar» la realidad efectiva del objeto de la fe; o siquiera la mayor racionalidad de la decisión por ella. Allí ya pisamos suelo extranjero: el incierto país de la dogmática. Pero, entonces, ¿en qué podemos tener fe? ¿A que fe nos impulsa la angustia sin traspasar los límites de la dogmática? Simplemente a ser conscientes de que podemos confiar en que la necesidad de la fe no es un absurdo, sino que resulta de nuestra propia condición espiritual. ¿Y cuál es la fe no dogmática; aquella fe a la que nos mueve nuestro espíritu angustiado para no recaer en la desesperación de quien se aferra a lo finito y se niega a sí mismo como espíritu que aspira a lo infinito? ¿Es la fe en Cristo, en Mahoma, en Buda, en la Tradición de la Santa Iglesia Católica o en la sola scriptura que reclama La Reforma? ¿No es acaso Kierkegaard un fundamentalista protestante? ¿No es él el apologeta del absurdo? ¿No es un fanático del Crucificado? Me cuesta -luego del análisis fenomenológico de El concepto de la angustia- pensarlo en esos términos. La angustia nos revela la posibilidad. Ahora bien, «como en la posibilidad todo es posible» y como la posibilidad somos nosotros mismos en tanto espíritu, ella le deja abierta a todos y cada uno de los hombres la posibilidad de la fe. Pero no en ninguna certeza confesional cualquiera, sino tan sólo simplemente - iy sin embargo es un consuelo tan grande!- en que todo, tal vez, tenga sentido, aunque éste se nos escape; en que la nada, quizás, no tenga la última palabra, aun cuando por lo pronto sólo escuchemos el silencio. Es la fe en un Absoluto que no podemos conocer, pero que sabemos con certeza indubitable que necesitamos, y que tal vez, pero sólo tal vez, de algún modo no se olvide por completo de nosotros. Es un ancla en la nada. Mas un sentido tal de la fe es todo lo contrario del fundamentalismo. Es la puesta a la luz del fundamento en el que -sin renunciar a las respectivas convicciones dogmáticas- todas las confesiones pueden encontrarse. Es éste el servicio que la fenomenología de la angustia puede prestarle a la religión. No creo que sea un servicio menor mostrar lo que la angustia -como la propia vida de Kierkegaard- representan: «el grito [desgarrado AG] de la subjetividad hacia lo que la supera ${ }^{27}$. Fe es sentir dentro de sí que el destino de ese grito no es retumbar en la nada.

27 Wahl, J., op. cit., p. 256. 